Remarks, - Much has been said with respect to the disadvantages and dangers attending dilatation with sponge tents, but if every precaution be taken to see that the tents vised are aseptic many of the dangers are avoided. The tents should always be kept air-tight if possible till required for use. I find a clear stoppered bottle answers best. When required, the tents should be thoroughly soaked in a fresh solution of ether and iodoform or glycerine and carbolic acid, the vagina should be syringed with some antiseptic, and then the tent should be passed through the speculum, taking care that they do not come into contact with the vaginal walls and thus carry septic matter into the interior of the uterus. The advantages of tents in such cases as the above are: Firstly, general practitioners are more accustomed to using them than any other dilators; secondly, they are less expensive than Hegar's dilators ; thirdly, they are less likely to cause laceration; fourthly, dilatation, although slower, is less painful; fifthly, the operation can be performed in many cases without an anæsthetic, and this in itself is a consideration to the country practitioner who may have no assistance at hand in these cases. Stantonbury, Bucks.

\section{LOCALISED INFLAMMATION OF THE POSTERIOR SUPERIOR QUADRANT OF THE TYMPANIC CAVITY.}

BY R. LAKE, F.R.C.S. ENG., L.R.C.P. LOND. \&c., PATHOLOGIST AND REgISTRAR TO THE HOSPITAL FOR DISEASES OF THH THROAT, GOLDEN-SQUARE

ReTENTION of inflammatory exudation behind the upper posterior quadrant of the membrana tympani is shown by redness and bulging of that part and is usually accompanied by a normal condition of the remainder of the membrane. This localised retention closely resembles that which takes place in the attic, in which pent-up fluid points through Schrapnell's membrane. If the tympanic cavity is carefully laid open by removal of its posterior wall, one can see how this shutting off of its posterior superior portion occurs the various structures which effect this are the tendon of the tensor tympani, the descending process of the incus, the stapes, stapedius and pyramid, and the chorda tympani. Any cause setting up inflammation in this region would, on account of the accompanying swelling, shut off this part from the general tympanic cavity. As this subchamber communicates directly with the antrum, all the secretion from this cavity is pent up behind the membrane and one may remove a very large quantity of mucus by irrigation through the Eustachian tube after incision. There is a slight risk of dividing the chorda tympani. I think it occurred to me in a case of the above variety, for after paracentesis there was numbness of that side of the tongue of several weeks' duration. 'The treatment consists of incision of the bulging membrane, with subsequent irrigation through the Eustachian tube by means of a catheter with a per cent. salt solution.

Seymour-street, Portman-square, W.

Dr. J. Rufus Tryon, Fleet-Surgeon to the flagship Chicago, has heen appointed Surgeon-General of the American Navy. He entered the Service thirty years ago.

British Medical Temperance Assoctation.The seventeenth annual meeting of the British Medical Temperance Association was held on Friday, the 19th inst., at the Temperance Hospital, Hampstead-road, London, Dr. B. W. Richardson, F.R.S., presiding. The annual report stated that there are 418 members in the Association, eighty-six student associates and one lay associate, all being personal akistainers. Twenty-eight new members had joined during the year, and there was a net increase of three. A northern counties branch has just been formed, of which Dr. Coley of Newcastle is president. After the business of the meeting a discussion on Cholera in relation to Alcohol was opened by Dr Richardson. He dealt with it under five heads: (1) the negligence produced amongst the people at large who rushed to drink through fear ; (2) its misuse by those affected; its effect being always mischievous ; (3) the absence of any physiological reason for giving it ; (4) its uselessness during the acute stage ; (5) its injuriousness during the stage of reaction The discussion was continued by Brigade-Surgeon Pringle Dr. Norman Kerr, Surgeon-General Francis, Dr. Morton and Dr. Ridze.

\section{d attirtor}

oF

\section{HOSPITAL PRACTICE, BRITISH AND FOREIGN.}

Nulla autem est alia pro certo noscendi via, nisi quamplurimas et mor borum et dissectionum historias, tum aliorum tum proprias collecta habere, et inter se comparare.-MoRgaGNI De Sed. et Caus. Morb., lib. iv. Procemium.

\section{WEST LONDON HOSPITAL.}

CHRONIC ULCER OF STOMACH ; PERFORATION OF DIAPHRAGM EMPYEMA; REMARKABLE ABSENCE OF GASTRIC

SYMPTOMS ; DEATH.

(Under the care of Dr. Donald W. C. Hood.)

CHronid ulcer of the stomach sometimes produces mos unexpected symptoms after perforation, and frequently it is quite impossible to diagnose the cause of the puzzling condition presented by a patient; this is more especiaily so when there has been nothing in the history of the patient to lead to a suspicion of gastric disease, and a notable feature in the history of this case was the complete absence of the usual symptoms which would have drawn attention to the stomach as being the primary source of disease. During the five weeks the patient was under constant observation there was no gastric pain or any inconvenience referable to digestion. The dense fibrous band which divided the viscus into two distinct cavities wa evidently of very old standing, and probably dated from that ulcerative process which gave rise to the initial hæmatemesis three years before. From the thickened cicatricial appearance of the walls of the cardiac end of the stomach it was concluded that ulceration had been in process for many months, if not from the time of the primary hæmorrhage. This part, cut off from the other, had gradually lost its function, and food passedalmost direct from the osophagus into what had become the only true stomach, thus coming but slightly into contact with the area of ulceration. The usual pain of gastric ulcer was absent. The globular swelling which appeared during the illness was probably due to the cardiac portion of the abnormal stomach distended with gas. The opening from the cesophagus was closely adherent to the fibrous ring dividing the two parts of the stomach, and it is quite possible that during life there had been but little, if any, communicetion between the two cavities; otherwise there would have been a large escape of gas on passing the tube.

A well-nourished, healthy looking girl was admitted into the West London Hospital on Dec. 14th, 1891. She was suffering severely from the ordinary and well-marked symptoms of acute pleurisy affecting the left side. The illness commenced suddenly seven days before her admission, the primary symptoms being a sharp, stabbing pain, accompanied by romiting. The girl, a barmaid, appeared to have led very abstemious life and stated that her general health had been excellent. Three years before this illness she had suffered from an attack of "bleeding from the stomach" and at that time had been dyspeptic. After the hæmorrhage her digestion had improved and she had since then been in good genera? health and had had no inconvenience referable to dyspepsia. From the general condition of the patient and the extreme severity of the symptoms it was concluded that the effusion, which appeared to fill the left chest, was purulent. After having been under observation in hospital for a few days, the chest was aspirated, thirty-eight ounces of pus of extreme fetor being removed. After the operation there was no change in the condition of the patient, the temperature remained high and there was no amelioration in the general symptoms. At this date a peculiar resonant globular swelling appeared in the epigastric region. A part from the shape theie could be but little doubt that it was the stomach distended with gas, but the markedly globular shape seemed to weigh against this opinion. The swelling remained for three or four days without giving rise to discomfort. On one occasion a tube was passed into the stomach, but without any discharo: of gas or diminution in the size of the swelling. As no relief followed the withdrawal of the fetid pus it was decided that Mr. Keetley should freely incise the chest. Unfortunately the operation was postponed owing to an attack of diphtheria 
which the patient contracted whilst in hospital. During this iliness the first definite symptom of stomach lesion occurreda sudden and copious hæmorrhage, which recurred on the following day. On Jan. 11th-the girl being well from diphtheria and but little affected by the hæmorrhage, her general health being decidedly improved-aspiration was again performed, but only two ounces of pus escaped. Five days later phlebitis of both femoral veins supervened and during this inflammatory attack it was not considered advisable to open the chest. The phlebitis passed ispidly away and a few days later Mr. Keetley made a free incision into the chest at the seventh interspace. No fluid ras found; the pleura was much thickened and a probe was easily passed into a cavity apparently seven or eight inches zoross. Three days after this operation the patient had a severe rigor and appeared to be in a critical condition. Under rreatment she improved and subsequently made real and substantial progress. She was able to take all kinds of food with appetite and relish. She sat up in bed and had no symptoms giving rise to anxiety. This improvement lasted for fourteen days, when another sharp attack of hæmatemesis occurred to the extent of twenty ounces. The hæmorrhage recurred again and again and the girl sank exhausted five days later.

Necropsy, twenty-four hours after death. -On opening the whest and abdomen a large cavity was found lying between the left lung and diaphragm. This cavity communicated with the interior of the stomach at its cardiac end by means of a perforation about an inch in diameter. The greater portion of the stomach was closely adherent to the under surface of the diaphragm. A second perforation from this part of the stomach passed into an abscess lying against the spleen. The whole stomach was slightly dilated, but the cardiac portion, contracted and globular in shape, with fibrous, thickened rugose walls, was completely cut off from the pyloric and dilated portion by a firm, constricting band which enclosed an opening of an inch and a half in diameter. Into this globular cavity passed the sinus, leading into the pleura, the orifice of the cesophagus and the perforation into the splenic abscess. The wall of the larger or pyloric part of the stomach was much thinner than normal and passed gradually into the bowel without a trace of the pylorus. In addition to this peculiar condition of the stomach there were purulent pericarditis and multiple hepatic abscesses.

\section{Suttedical Socictites.}

\section{ROYAL MEDICAL AND CHIRURGICAL SOCIETY.}

\section{Adjourned Discussion on a Case of Cystic Uterine Myoma.-} Enterorraphy by Invagination.

AN ordinary meeting of this Society was held on May 23rd, Mr. Chinton Dant, Vice-President, in the chair.

The adjourned discussion on Mr. Alban Doran's paper was resumed by Dr. Herbert SPENCER, who showed specimens and related cases in support of the hypothesis that these cysts were due to lymphangiectasis. He asked why the cystic tumour had been tapped before operation, which he beld to be a dangerous procedure and never to be adopted unless the tumour was obviously malignant or the patient very ill with acute bronchitis or pneumonia. He had seen several apparently simple cases of ovarian cyst in which after tapping inflammation had been set up and the prognosis thereby made extremely grave. Tapping was likely to provoke formation of adhesions and to disseminate papillomatous growths should they be present. liemarking on the treatment of the pedicle, he said that in Mr. Doran's case only the posterior layer of the broad ligament had been dissected $\mathrm{pp}$ by the tumour and the treatment was consequently somewhat difficult. $\mathrm{He}$ mentioned a case in which an enormous multilocular tumour of the broad ligament weighing seventy pounds required enucleation and hysterectomy had also to be performed. The peritoneum had been stripped up to such an extent that after enucleation of the growth it could not be brought down again. The lower part of the cavity was therefore stuffed with iodoform gauze, which was later replaced by a drainage-tube.

The patient made a good recovery. Dr. RoUTH thought that there might be cases in which tapping was allowable in order to arrive at a diagnosis, and he quoted one to illustrate this. If the trocar were small and aseptic the procedure was practically devoid of danger. If a large trocar were used there was great risk and he had collected statistics showing a mortality of over 40 per cent. amongst cases so treated. He enumerated four varieties of fibro-cystic tumours, and referred to cases illustrating them which he had recorded in his Lettsomian Lectures. He pointed out that a peculiar bruit was audible over these tumours not often met with in ovarian cysts. It was limited to a certain position, which was not that of the bruit of pregnancy, for it could be heard high up in the abdomen over localised areas transmitted cardiac sounds might also be heard. He considered that justice had not been done to the electrical treatment, under which some cases of both fibroids and fibro-cystic tumours would disappear, and if they did not disappear they might be. come stationary and their further growth might be prevented. Mr. DoraN, in reply, said he had frequently observed the condition of enlarged lymphatics at operation, and for this reason he believed in the lymphatic theory of origin of fibrocystic tumours. He agreed that it was objectionable to tap an ovarian cyst, but when it was inevitable that a patient with a large ovarian cyst should be kept waiting for operation, and if, meanwhile, she suffered from pressure symptoms, tapping would relieve her and enable her to gain strength for operation. In any instance of uterine fibrocystic tumour in which the diagnosis was certain he would not resort to tapping. He had treated the stump extraperitoneally because it was very soft and degenerated, and the remains of the capsule round it had been damaged during the operation. Coagulable fluid, though suggestive of uterine cyst, was sometimes met with in ovarian cyst. He had only heard a bruit in extremely malignant ovarian sarcoma-he had not met with it in cases of cystic uterine fibroids.

Mr. STANLEX BoyD read a communication on Enteror. raphy by Invagination (Maunsell's operation), with a case of Artificial Anus treated by this method. Maunsell's method of performing enterectomy and enterorraphy was first described and reference was male to a case treated by this method by Mr. Maunsell in which the operation appeared to be successful although the patient died. Details were given of a case of artificial anus of six months' duration, left after a strangulated right femoral hernia, which was treated by herniotomy without opening the sac. The history received with the patient, together with the state of matters found upon examination, led to the tentative diagnosis of cæcal fistula and to the commencement of an operation for its extraperitoneal closure. This operation showed that a loop of small intestine had sloughed and that the lower end of the bowel lay completely closed, within the ring, adherent to the upper end. The pared ends were united by Maunsell's method, and the patient recovered without a bad symptom. The opinion was expressed that Maunsell's method of enterroraphy was the simplest of the methods at present before the profession, no bone tubes or other special apparatus being required; that it was as quick as, if not quicker than, any of them ; and that there was sufficient evidence in favour of its safety to warrant a further trial. - Mr. WATson CHEYNE said he had recently performed this operation, though with an unsuccessful result. It was very simple and effected a great saving of time. A child six months old was brought into hospital with an intussusception of a few hours' standing nearly protruding from the anus. It appeared to be quite reduced by inflation of the rectum, but next day it had returned. The peritoneum being opened he found that blowing up the rectum had almost reduced the intussusception, leaving a small knot of intestine, but the $t \in n$ sion had been so great that the coats of the gut were splitting, so he resected the affected portion by Mr. Maunsell's plan, which only took a few minutes. The patient, however, was very collapsed and death took place the following morning.-Mr. MAUNSELL hoped that the effect of discussion would be to induce surgeons to adopt a more rational plan of dealing with certain cases of intestinal surgery. He then explained, with the aid of diagrams, the procedure he advocated.-Mr. BoYD, in reply, said that though he had effected the suture of the intestine through a very small abdominal wound, yet he had very little difficulty in returning the gut, as its thickness was so very slightly increased by this method of enterorraphy. 